\title{
Fasciolopsis buski
}

National Cancer Institute

\section{Source}

National Cancer Institute. Fasciolopsis buski. NCI Thesaurus. Code C122309.

A species of parasitic tremadoda flatworms in the family Fasciolidae. The life cycle of F. buski involes snails as the intermediate host and pigs and humans as the definitive host. It is the largest intestinal fluke of humans. 